\title{
Epidemiological and Clinical Features of COVID-19 Patients at National Emergency Hospital Wisma Atlet Kemayoran, Jakarta, Indonesia
}

\author{
Agus Dwi Susanto ${ }^{1,2}$, Anna Rozaliyani ${ }^{1}$, Budi Prasetyo ${ }^{2}$, Heidy Agustin ${ }^{2}$, Hario Baskoro',2*, Arief Riadi Arifin ${ }^{1,3}$, Satria Pratama ${ }^{1,3}$, \\ Jamal Zaini ${ }^{1,2}$, Bambang Dwi Hasto ${ }^{3}$, Tugas Ratmono ${ }^{3}$, Ary Indriana Savitri ${ }^{4}$, Erlang Samoedro ${ }^{1}$, Bahtiar Husain ${ }^{1}$, Arifin Nawas ${ }^{2}$, \\ Erlina Burhan ${ }^{1,2}$ \\ ${ }^{1}$ National Medical Team COVID-19, the Indonesian Society of Respirology, Jakarta, Indonesia, ${ }^{2}$ Department of Pulmonology and Respiratory Medicine, \\ Persahabatan General Hospital, Faculty of Medicine Universitas Indonesia, Jakarta, Indonesia, ${ }^{3}$ National Emergency Hospital Wisma Atlet Kemayoran, \\ Jakarta, Indonesia, ${ }^{4}$ Siena Clinical: Academic Research Organization, Jakarta, Indonesia
}

\begin{abstract}
The emergency hospital is intended to prevent transmission of COVID-19 in the community by isolating patients without symptoms, with mild or moderate symptoms. This study evaluated the clinical characteristics and outcomes of COVID-19 patients who were admitted to this facility. This retrospective study reviewed data of patients treated at the National Emergency Hospital Wisma Atlet Kemayoran in Jakarta, Indonesia, from March 23 to April 30, 2020. Patient characteristics (clinical symptoms, laboratory test results, Chest X-Ray, SARS-CoV-2 immunoserology, and RT-PCR results from nasopharyngeal/ oropharyngeal preparations) were compared between severity groups. There were 413 COVID-19 cases analyzed, of which 190 (46\%) were asymptomatic, $93(22.5 \%)$ were mild, and 130 (31.5\%) were moderate cases. Most asymptomatic cases were male, with young age, and without comorbidity. Mild cases were dominated by female and young patients, while most moderate cases were male and older patients. The number of patients with comorbidities was higher in mild and mod-erate cases. The patient's overall outcome was good and did not differ based on the severity of symptoms. Despite the many challenges, patients with moderate symptoms can be safely treated in the emergency hospital.
\end{abstract}

Keywords: asymptomatic, COVID-19, emergency hospital

\section{Introduction}

By the time the World Health Organization (WHO) declared a pandemic of COVID-19 in early March 2020, the disease had already reached many countries worldwide, including Indonesia. Indonesia is a middle-income country with per capita health expenditure among the lowest in the category. ${ }^{1}$ The COVID-19 pandemic has been expected to hit low- and middle-income countries (LMICs) the hardest. The low socioeconomic status of the population, as characterized by overcrowded living conditions, limited access to daily basic needs (e.g., food, clean water), and reliance on daily earnings, makes physical distancing and lockdown almost impossible. Furthermore, the care of COVID-19 patients is challenging as the already limited health care capacities become quickly overwhelmed.

Confirmed COVID-19 was first reported in Indonesia on March 2, 2020; ${ }^{2}$ since then, Jakarta became the first and ongoing epicenter. The number of positive cases had risen dramatically to more than 250,000 by the time this manuscript was prepared, and 9,800 deaths were recorded, the highest in Southeast Asia. ${ }^{3}$ During the early phase of the pandemic, Indonesia faced a challenging situation,

Correspondence*: Hario Baskoro, National Medical Team COVID-19, Indonesian Society of Respirology (PDPI), Jl. Cipinang Baru Bunder No.19, Cipinang, Jakarta, Indonesia, 13340, E-mail: hario.baskoro.md@gmail.com, Phone: +62 214705685 including lack of personal protective equipment (PPE), medical supplies and diagnostic tools, unequal medical services distribution, and no standardized national guidelines. ${ }^{4,5}$ This situation was complicated by inadequate/inconsistent public information from the government. One of the recommendations for handling the COVID-19 pandemic in a resource-limited setting is shifting public facilities into emergency hospitals. The Indonesian Government adopted this strategy by converting four apartment towers of Wisma Atlet Kemayoran in Jakarta into an emergency hospital to anticipate the surge of new cases in Jakarta. Wisma Atlet Kemayoran has a total of 24,000 beds at maximum capacity. ${ }^{6}$ These facilities were intended to isolate asymptomatic, mild, and moderate cases to stop community transmission. Routine monitoring was undertaken on each case, with those identified with worsening conditions to be transferred to referral hospitals. ${ }^{7}$ The emergency hospitals in Wuhan, China (such as Huoshenshan Hospital and Leishenshan Hospital) proved to approach disease containment successfully. ${ }^{8}$ The characteristics of patients in this kind of emergency hospital in LMICs settings are still largely unknown, especially during the early phase of the pandemic.

Received : July 5, 2021

Accepted : July 27, 2021

Published: July 31, 2021 
In this study, the clinical characteristics, therapies, and outcomes of COVID-19 patients treated in the emergency hospital were evaluated.

\section{Method \\ Study Design and Population}

This retrospective study used data from all confirmed COVID-19 patients admitted to the National Emergency Hospital Wisma Atlet Kemayoran, Jakarta, from March 23 to April 30, 2020. Patients were diagnosed according to the criteria of World Health Organization (WHO) interim guidance. Patients with complete data of clinical, radiological, basic laboratory results were included in the analysis. The laboratory-confirmed case was defined as a case with a positive result on real-time reverse transcription polymerase chain reaction (RT-PCR) for SARS$\mathrm{CoV}-2$ in either the nasal or pharyngeal swab specimens irrespective of the clinical signs and symptoms.

\section{Data Collection}

Data of all patients during the study period were extracted from the paper-based medical records into an electronic database. Age was recorded as continuous data but classified into three groups; 0-19 years, 20-49 years, and older than 50 years. Data related to signs and symptoms and the presence of comorbidity were recorded at admissions. The recorded symptoms were cough, sputum production, fever, dyspnea, sore throat, cold/runny nose, and anosmia. Comorbidities such as hypertension, diabetes, heart disease, asthma, and arthritis were recorded based on anamnesis. The peripheral blood test was taken at admission and measured hemoglobin, lymphocyte, white blood cell differential count, and platelets. Serological tests for detecting IgG and IgM antibodies against severe acute respiratory syndrome coronavirus 2 (SARS-CoV-2) were performed using commercially available immunochromatographic test (ICT) method with reactivity reported as IgG, IgM, or both. Chest XRay (CXR) was used as a simple imaging study for all new cases during admission in this facility and reported as normal, increased broncho vascular markings, and consistent pneumonia. Real-time reverse transcription polymerase chain reaction (RT-PCR) for SARS-CoV-2 detection conducted from nasal or pharyngeal swab specimens in the central laboratory based on standard WHO protocol. The RT-PCR tests were measured on day one or day two, day 14, and day 15 as the end date of the isolation period.

Cases were classified into three different clinical classifications, i.e., asymptomatic, mild, and moderate, based on symptoms, laboratory, and radiological findings. An asymptomatic case is defined as no symptoms with normal laboratory and CXR findings despite a positive SARS-CoV-2 RT-PCR test. A mild case is a positive SARS-CoV-2 RT-PCR with acute non-specific upper res- piratory tract symptoms but no sign of pneumonia. A moderate case is defined as positive SARS-CoV-2 RTPCR with clinical findings consistent with mild pneumonia but where the patient does not require hospitalization/is still able to perform daily activities. This clinical COVID-19 classification was under the direction of the Ministry of Health of the Republic of Indonesia COVID19 guidelines in March 2020. ${ }^{9}$ Since the nationally endorsed guidelines were not established at that time, clinical management of COVID-19 during the early phase of the pandemic in Indonesia was based on the consensus of five local professional organizations (5-OP/5 Organisasi Profesi), i.e., Indonesian Society of Respirology, Indonesian Society of Internal Medicine, Indonesian Heart Association, Indonesian Society of Anesthesiologists and Intensive Therapy, and Indonesian Pediatric Society. ${ }^{10}$ Data regarding medication and clinical outcomes during hospitalization were recorded.

\section{Outcome Measures}

The first day of admission was recorded as the start of hospitalization, while discharge from the hospital was recorded as the end of hospitalization. Clinical outcomes were classified into whether recovery was reached or not. Recovered cases were defined as two consecutive negative SARS-CoV-2 RT-PCR results based on WHO guidelines. Furthermore, the conversion time-duration in days until RT-PCR result turned negative-and length of stay-duration of hospitalization in days-were also evaluated. The cases were followed up until April 30, 2020.

\section{Data Analysis}

Patients' demographic information and clinical characteristics were tabulated based on clinical classification of the disease for descriptive purposes. Differences between asymptomatic, mild, and moderate cases of COVID-19 were evaluated and tested either using one-way ANOVA or Kruskal-Wallis for continuous variables and either using Pearson's Chisquare or Fisher's exact test for categorical variables, where appropriate. Statistical significance was considered to be a two-sided p-value $<0.05$. All analyses were performed using SPSS Version 25.0 for Mac (SPSS Inc., Chicago, IL, USA).

\section{Result \\ Presenting Characteristics}

There were 1,070 cases admitted early in the pandemic, with 828 cases classified as COVID-19 confirmed cases and 415 discarded COVID-19 based on WHO case definition. Of the total confirmed cases, 382 cases had no CXR, 17 cases with no lab test, and 16 cases had no clinical baseline data. Four hundred thirteen cases were included in the analysis with a complete data set, with $55.4 \%$ (229) male and $44.6 \%$ (184) female. The mean age was 39.9 years old, with the majority belonging to the productive-age group (20-49 age range). Older cases 
( $>50$ years) were more likely to be classified as moderate cases as compared to the younger groups. In general, the most common symptoms reported at onset were cough, followed by fever, dyspnea, sore throat, runny nose, and anosmia. Both in mild and moderate cases, the most common symptoms found were cough, fever, and dyspnea. The $10 \%$ of cases had pre-existing comorbidities, of which hypertension and diabetes were the commonest. Those without comorbidity were more likely to be in the asymptomatic group, as seen in Table 1.

\section{Laboratory and Radiologic Findings}

Abnormal laboratory findings such as reactive rapid serology test increased NLR, and lymphopenia was commonly reported. Other notable laboratory findings were thrombocytopenia and leucopenia. However, these laboratory findings did not differ based on clinical classification, as seen in Table 2. The normal radiologic finding was found in nearly half of all initial Chest X-Ray examinations, and all moderate cases had CXR consistent with pneumonia. Increased broncho vascular markings were found more frequently in mild cases than asymptomatic cases.

Table 1. Clinical Characteristics of COVID-19 Patients Admitted to National Emergency Hospital Wisma Atlet Kemayoran

\begin{tabular}{|c|c|c|c|c|c|}
\hline \multirow[t]{2}{*}{ Characteristics } & \multirow{2}{*}{$\begin{array}{l}\text { Total } \\
(n=413)\end{array}$} & \multicolumn{3}{|c|}{ Clinical degree } & \multirow{2}{*}{ p-value } \\
\hline & & $\begin{array}{l}\text { Asymptomat } \\
\quad(n=190)\end{array}$ & tic $\begin{array}{c}\text { Mild } \\
(n=93)\end{array}$ & $\begin{array}{c}\text { Moderate } \\
(n=130)\end{array}$ & \\
\hline \multicolumn{5}{|l|}{ Sex } & 0.031 \\
\hline Male & $229(55.4)$ & $103(54.2)$ & $43(46.2)$ & $83(63.8)$ & \\
\hline Female & $184(44.6)$ & $87(45.8)$ & $50(53.8)$ & $47(36.2)$ & \\
\hline Age (in years) & $39.9(14.2)^{2}$ & $\begin{array}{r}38.3 \\
(14.7)\end{array}$ & $\begin{array}{r}37.1 \\
(11.5)\end{array}$ & $\begin{array}{r}44.3 \\
(14.1)\end{array}$ & $<0.001^{3}$ \\
\hline \multicolumn{2}{|l|}{ Age } & & & & $<0.001^{1}$ \\
\hline 0-19 years & $30(7.3)$ & $20(10.5)$ & $4(4.3)$ & $6(4.6)$ & \\
\hline 20-49 years & $267(64.6)$ & $122(64.2)$ & $75(80.6)$ & $70(53.8)$ & \\
\hline$>50$ years & $116(28.1)$ & $48(25.3)$ & $14(15.1)$ & $54(41.5)$ & \\
\hline \multicolumn{6}{|l|}{ Symptoms } \\
\hline Cough & $93(22.5)$ & $0(0.0)$ & $61(65.6)$ & $32(24.6)$ & $<0.001^{4}$ \\
\hline Sputum production & n $15(3.6)$ & $0(0.0)$ & $13(14.0)$ & $2(1.5)$ & $<0.001^{4}$ \\
\hline Fever & $59(14.3)$ & $0(0.0)$ & 39 (41.9) & $20(15.4)$ & $<0.001^{4}$ \\
\hline Dyspnea & $27(6.5)$ & $0(0.0)$ & $14(15.1)$ & $13(10.0)$ & $<0.001^{4}$ \\
\hline Sore throat & $22(5.3)$ & $0(0.0)$ & $15(16.1)$ & $7(5.4)$ & $<0.001^{4}$ \\
\hline Cold/runny nose & $20(4.8)$ & $0(0.0)$ & $10(10.8)$ & $10(7.7)$ & $<0.001^{4}$ \\
\hline Anosmia & $6(1.5)$ & $0(0.0)$ & $5(5.4)$ & $1(0.8)$ & $0.002^{4}$ \\
\hline \multicolumn{5}{|l|}{ Pre-existing comorbidity } & $<0.001^{1}$ \\
\hline Yes & $43(10.4)$ & $7(3.7)$ & $18(19.4)$ & $18(13.8)$ & \\
\hline No & $370(89.6)$ & $183(96.3)$ & $75(80.6)$ & $112(86.2)$ & \\
\hline \multicolumn{5}{|l|}{ Comorbidities } & $<0.001^{1}$ \\
\hline None & $370(89.6)$ & $183(96.3)$ & $75(80.6)$ & $112(86.2)$ & \\
\hline Hypertension & $17(4.1)$ & $1(0.5)$ & $7(7.5)$ & $9(6.9)$ & \\
\hline \multicolumn{6}{|l|}{ Diabetes } \\
\hline and Hypertension & $4(1.0)$ & $2(1.1)$ & $0(0.0)$ & $2(1.5)$ & \\
\hline Diabetes & $8(1.9)$ & $3(1.6)$ & $1(1.1)$ & $4(3.1)$ & \\
\hline Heart disease & $3(0.7)$ & $0(0.0)$ & $2(2.2)$ & $1(0.8)$ & \\
\hline Asthma & $2(0.5)$ & $0(0.0)$ & $2(2.2)$ & $0(0.0)$ & \\
\hline Arthritis & $1(0.2)$ & $0(0.0)$ & $1(1.1)$ & $0(0.0)$ & \\
\hline
\end{tabular}

Notes: Values are means with standard deviations for continuous variables and $\mathrm{n}$ $(\%)$ for frequencies. ${ }^{1}$ Pearson Chi-square, ${ }^{2}$ The median with the interquartile range is presented, ${ }^{3} \mathrm{ANOVA},{ }^{4}$ Fisher's Exact Test

\section{Intervention and Outcome}

Among 413 cases, data related to therapy were available in only 108 cases. All cases received vitamin C, 5.6\% of them also received Azithromycin, $10.2 \%$ Oseltamivir and Azithromycin, $4.6 \%$ Oseltamivir and Hydrochloroquine, 7.4\% Oseltamivir and Chloroquine, $28.7 \%$ Oseltamivir with Hydrochloroquine and Azithromycin, 10.2\% Oseltamivir with Chloroquine and Azithromycin, and $3.7 \%$ a combination of Chloroquine with Azithromycin and Levofloxacin. No adverse effects were reported in the majority of the cases $(83.1 \%)$. Almost all patients recovered, and the median length of stay at the facility was 24 days. Conversion time varied between patients, with around half of them converted in less than 14 days and the other half in more than 14 days. Clinical classification did not seem to correlate with conversion time and length of stay (Table 3 ).

Table 2. Laboratory and Radiologic Findings of COVID-19 Patients Admitted to National Emergency Hospital Wisma Atlet Kemayoran

\begin{tabular}{|c|c|c|c|c|c|}
\hline \multirow[t]{2}{*}{ Characteristics } & \multirow{2}{*}{$\begin{array}{c}\text { Total } \\
(n=413)\end{array}$} & \multicolumn{3}{|c|}{ Clinical degree } & \multirow{2}{*}{ p-value } \\
\hline & & $\begin{array}{c}\text { Asymptomatic } \\
(n=190)\end{array}$ & c $\begin{array}{c}\text { Mild } \\
(n=93)\end{array}$ & $\begin{array}{l}\text { Moderate } \\
(n=130)\end{array}$ & \\
\hline $\begin{array}{l}\text { Thrombocytopenia } \\
\qquad(<150000 / \mathrm{uL})\end{array}$ & $7(1.7)$ & $2(1.1)$ & $1(1.1)$ & $4(3.1)$ & 0.391 \\
\hline $\begin{array}{l}\text { Leucopenia } \\
\qquad(<4000 / \mathrm{uL})\end{array}$ & $2(0.5)$ & $1(0.5)$ & $0(0.0)$ & $1(1.1)$ & $0.50^{1}$ \\
\hline Lymphopenia $(<20 \%)$ & $45(10.9)$ & 17 (8.9) & $9(9.70$ & $19(14.6)$ & $0.25^{2}$ \\
\hline Increased NLR (>3.13) & $76(18.4)$ & $31(16.3)$ & $15(16.1)$ & $30(23.1)$ & $0.25^{2}$ \\
\hline $\begin{array}{l}\text { Reactive rapid } \\
\text { serology test }\end{array}$ & $202(48.9)$ & $89(46.8)$ & $14(47.3)$ & $69(53.1)$ & $0.78^{2}$ \\
\hline $\begin{array}{l}\text { Chest X-ray } \\
\text { Consistent with }\end{array}$ & & & & & $<0.0011$ \\
\hline $\begin{array}{l}\text { Pneumonia } \\
\text { Increased broncho }\end{array}$ & $130(31.5)$ & $0(0.0)$ & $0(0.0)$ & $130(100)$ & \\
\hline vascular markings & $110(26.6)$ & $71(37.4)$ & 39 (41.9) & 0 & \\
\hline Normal & 173 (41.9) & $119(62.6)$ & $44(58.1)$ & 0 & \\
\hline
\end{tabular}

Notes: Values are n (\%) for frequencies, ${ }^{1}$ Fisher's Exact Test, ${ }^{2}$ Pearson Chi-square

Table 3. Clinical Outcomes of COVID-19 Patients Admitted to National Emergency Hospital Wisma Atlet Kemayoran

\begin{tabular}{|c|c|c|c|c|c|}
\hline \multirow[t]{2}{*}{ Characteristics } & \multirow{2}{*}{$\begin{array}{c}\text { Total } \\
(n=413)\end{array}$} & \multicolumn{3}{|c|}{ Clinical degree } & \multirow{2}{*}{ p-value } \\
\hline & & $\begin{array}{l}\text { Asymptomatic } \\
\qquad(n=190)\end{array}$ & ic $\begin{array}{c}\text { Mild } \\
(n=93)\end{array}$ & $\begin{array}{c}\text { Moderate } \\
(\mathrm{n}=130)\end{array}$ & \\
\hline Outcome & & & & & 0.141 \\
\hline Recovered & $410(99.3)$ & $190(100)$ & $91(97.8)$ & $129(99.2)$ & \\
\hline Referred & $1(0.2)$ & $0(0.0)$ & $1(1.1)$ & $0(0.0)$ & \\
\hline $\begin{array}{l}\text { Discharged by } \\
\text { patient's request }\end{array}$ & $2(0.5)$ & $0(0.0)$ & $1(1.1)$ & $1(0.8)$ & \\
\hline \multicolumn{6}{|l|}{ Conversion Time } \\
\hline Less than 14 days & $196(47.5)$ & $80(42.1)$ & $48(51.6)$ & $68(52.3)$ & $0.13^{2}$ \\
\hline 14 days or more & $217(52.5)$ & $110(57.9)$ & $45(48.4)$ & $62(47.7)$ & \\
\hline Length of stay (in days) & $24(15) 4$ & $25(16)$ & $22(16)$ & $24(11)$ & $0.20^{3}$ \\
\hline
\end{tabular}

Notes: Values are n (\%) for frequencies, ${ }^{1}$ Fisher's Exact Test, ${ }^{2}$ Pearson ChiSquare, ${ }^{3}$ Kruskal Wallis Test, ${ }^{4}$ The median with the interquartile range is presented. 


\section{Discussion}

\section{Confirmed COVID-19 Case Proportion}

There were 828 confirmed cases of COVID-19 from a total of 1070 suspected cases admitted to the national emergency hospital during the early phase of the pandemic. A confirmed case is based on the WHO COVID case definition, of which positive SARSCoV-2 RT-PCR must be detected from nasopharyngeal/oropharyngeal swab. ${ }^{11}$ The number of cases not included in the analysis was 415 cases due to incomplete data collection. During the early phase of the pandemic in this emergency hospital, the data management of all patients was based mainly on manual/paper-based records since the paperless system was still in preparation and most health care providers were volunteers.

Additionally, 413 with a complete data set were analyzed. Clinical classification presenting in this study mainly was asymptomatic cases (46\%), followed by moderate and mild cases, respectively. The high proportion of asymptomatic COVID-19 confirmed cases might be due to the nature of this national facility that intended to take care of asymptomatic, mild, and moderate cases. A study by Young et al., Michelen et al., Zhao et al. conducted in general hospitals in each country showed about $60-80 \%$ of cases reported asymptomatic to the mild clinical condition. ${ }^{11-13}$ Another study in an emergency hospital setting showed a different clinical condition proportion in which asymptomatic cases were less than $10 \% .{ }^{11,13}$

\section{General Characteristic of the Confirmed Case}

Confirmed case prevalence in males was about 1.24 times higher than in females in this study. This result was consistent with two other previous studies that showed higher prevalence in the male population. ${ }^{12,14}$ Almost $92 \%$ of the cases were younger than 60 years old with a mean age of $39,94 \pm 14,17$ years old. This characteristic was slightly different from what Ma et al. reported in their studies where the median age of 49.8 years old. ${ }^{14}$ In that study, severe cases were also included. Age as a predicting factor of COVID-19 severity was also reported ( $\geq 50$ years old). ${ }^{14}$ This was consistent with the fact that younger people have more robust immune responses and tend to have a milder infection compared to their elder counterparts. ${ }^{15}$ Therefore, is it likely that most asymptomatic covid confirmed cases were relatively younger. ${ }^{12,14,16}$ This study presented that almost $90 \%$ of the cases had no known comorbidity. Of those with comorbidities, hypertension and diabetes mellitus were the commonest. This characteristic is in line with a sys-tematic review by $\mathrm{Ma}$ et al. that showed cerebrovascular disease, hypertension, and diabetes mellitus were the most prevalent comorbidities in COVID-19 with proportions of $6.75 \%, 4.48 \%, 4.43 \%$ consecutively. ${ }^{14}$

\section{Clinical, Imaging, and Laboratory Characteristics of Confirmed Cases}

In this study, the most common symptoms were cough and fever in almost $22.5 \%$ and $14.3 \%$ of cases, respectively, followed by dyspnea, sore throat, and cold, in order. Noor et al. reported that nearly $80 \%$ of the cases showed respiratory symptoms, with the most prevalent cough and fever symptoms. ${ }^{17}$ Another systematic review reported gastrointestinal and neurologic symptoms following respiratory symptoms. ${ }^{14}$ The differences between studies might be affected by country demography, population subjectivity, and subject honesty in each study setting. This study did not record other gastrointestinal and neurological symptoms because it was based on early manual medical records limited to basic main symptoms.

Chest X-Ray findings showed that about $40 \%$ of cases had a normal description, and 30\% were consistent with pneumonia in all moderate cases. A study by Ma et al. reported 33\% of abnormal imaging findings in infiltrate and crepitation based on CT scan. ${ }^{14}$ High-resolution CT scan of the chest was not possible in these facilities. Therefore CXR was conducted as a simple and affordable imaging modality. This study showed that CXR could be used as a baseline imaging in resource-limited settings. It was found that the reactive result of rapid serology test only in $50 \%$ of confirmed cases. This finding then led to differences in previous studies results reporting rapid serology test sensitivity, about $62.2 \%-83.8 \%$ for asymptomatic and symptomatic cases. ${ }^{18,19}$ Differences between results might be affected by the examination method as well as the sensitivity and specificity of the examination tools in each study.

Routine laboratory tests in this study were mainly within normal limits. About $20 \%$ of cases with abnormal findings included lymphopenia, leucopenia, and thrombocytopenia. This finding was in line with other studies. ${ }^{11,12,14,20}$ Interestingly, an NLR value of more than 3.13 was also found in asymptomatic and mild clinical degree cases. Contrary to recent study findings, which reported that NLR value $>3.13$ could be used as a reliable indicator of severe COVID-19. ${ }^{21}$ The different results found might be related to the variability of country demography, clinical degree, and/or individual systemic immune response used in each study.

This study found no significant relationship between clinical condition and laboratory findings mentioned previously. A previous systematic review reported thrombocytopenia, lymphopenia, and elevated d-dimer as negative prognostic factors. ${ }^{13}$ However, this study could not conclude since most cases were asymptomatic and mild. Lymphopenia and increased NLR appeared higher in the moderate cases than the asymptomatic and mild cases, although not statistically significant. Another study also reported lymphopenia $(8.1 \%)$ and thrombocytopenia $(2.7 \%)$ in asymptomatic cases. ${ }^{18}$ What might be inter- 
esting is that the proportion of lymphopenia and thrombocytopenia in asymptomatic case reporting was $37.8 \%$ and $28.6 \%$, respectively, higher than previously reported. Innate and adaptive immunity in this study population might differ in response to SARS-CoV-2, especially in asymptomatic and mild cases. Further study is needed to delineate this assumption.

\section{Outcomes}

Ninety-nine percent of cases in this study were recovered based on negative SARS-CoV-2 RT-PCR testing. Of note, $100 \%$ of asymptomatic cases recovered, only $1.1 \%$ (1) mild case was referred to the referral hospital due to worsening condition, and $0.5 \%$ ( 2 patients) were discharged by request. None of the moderate cases became progressed even though they had evidence of pneumonia based on CXR and were given standard therapy. Since there is no solid evidence for COVID definitive treatment, standard therapy might be still be needed and might play a role in COVID-19 recovery, especially in asymptomatic, mild, and moderate cases.

This is different from the results of the study by Tian et al., where $45(17.2 \%)$ patients were discharged or recovered, $214(81.7 \%)$ stayed in the hospital, and three patients died. ${ }^{16}$ Zhao et al. stated that out of 77 patients, 64 patients were discharged, recovered, eight remained in treatment, and five died. Five patients died, and three of them were confirmed positive to COVID-19. ${ }^{11}$ The difference in the outcome of treatment in this study compared to other studies might be due to the emergency hospital function of treating asymptomatic, mild, and moderate patients.

The mean length of stay in this study was 24 days and was similar across asymptomatic, mild, or moderate cases. Conversion time among groups was also similar, with $52.3 \%$ cases virologically converted after 14 days. It was because, during the early phase of the pandemic, only one central laboratory was able to run SARS-CoV-2 RTPCR tests and needed 5-7 working days to acquire the results. Young et al. found that from 18 subjects with confirmed COVID-19 in Singapore, there was a prolonged duration of conversion to 24 days after symptoms onset. ${ }^{12}$ Zhou et al. obtained a median duration of viral retention of 20 (17-24) days from the onset in surviving patients and a maximum of 37 days. ${ }^{21}$

This study is among the first to have reported patients' clinical characteristics and outcomes with COVID-19 treated at the emergency hospital in Indonesia. However, this study's limitations were that patients with incomplete data could not be included in the analysis. CXR data was missing in more than $40 \%$ of all COVID-19 patients in our hospital during the study period. This may cause the selection of study subjects, although we believe that this missingness was random and did not influence the validity of our findings.

\section{Conclusion}

Clinical characteristics of mild and asymptomatic cases were similar, but moderate cases with signs of pneumonia are commonly found in this study. Asymptomatic, mild, and moderate COVID-19 confirmed cases mainly were recovered. Only a small proportion developed a severe and progressive disease that needs further hospitalization. In emergency COVID care for mild/asymptomatic/moderate cases, it was still necessary to monitor the patients for progressive disease and stop community transmission in resource-limited settings. Even a moderate clinical condition with signs of pneumonia could be treated/monitored safely in an emergency hospital despite many challenges. Further studies should be directed towards improving the quality of care and optimizing the role of the emergency hospital during the pandemic.

\begin{abstract}
Abbreviations
WHO: World Health Organization; LMICs: low- and middle-income countries; 5-OP: 5 organisasi profesi; ANOVA: analysis of variance; COVID-19: coronavirus disease 2019; CT: computed tomography; CXR: Chest X-Rays; NLR: neutrophil to lymphocyte ratio; ICT: immunochromatographic test; LMIC: low- and middle-income countries; PPE: personal protective equipment; RT-PCR: reverse transcription polymerase chain reaction; SARS-CoV-2: severe acute respiratory syndrome coronavirus 2 .
\end{abstract}

Ethics Approval and Consent to Participate

This study was approved by The Ethics Committee of the Faculty of Medicine Universitas Indonesia (No. KET636/UN2.F1/ETIK/PPM.00.02/2020).

\section{Competing Interest}

The authors reported no potential competing interests.

\section{Availability of Data and Materials}

The datasets generated and analyzed during the current study may be available from the corresponding author on reasonable request.

\section{Authors' Contribution}

$\mathrm{ADS}, \mathrm{AR}$, and $\mathrm{BP}$, were responsible for the study concept and design. ARA, SP, BDH, and TR contributed to data collection. AIS, ES, and HA performed data analysis and interpretation. JZ and HB prepared the first draft of the manuscript. $\mathrm{BH}, \mathrm{AN}$, and $\mathrm{EB}$ provided scientific input and revision of the manuscript. All authors critically reviewed and approved the final version of the manuscript.

\section{Acknowledgment}

The authors gratefully acknowledged the doctors \& medical team from Indonesia National Emergency Hospital - Wisma Atlet Kemayoran for the help on patients management. 


\section{References}

1. World Health Organization. Current health expenditure per capita (current US\$); 2020 [cited 2020 Sep 21].

2. Coronavirus Disease 2019 (COVID-19) situation report-1; 2020.

3. Worldometer COVID-19 coronavirus pandemic; 2020 [cited 2020 Sep 22].

4. Pinandita A (The JP. COVID-19: Indonesia calls for global coopera-tion to overcome medical supply shortage; 2020.

5. Ghalia G, Arbi IA. Shortage of PPE, medical workers hindering COVID-19 fight, says Terawan. The Jakarta Post; 2020

6. Kementerian Komunikasi dan Informatika Republik Indonesia. Miliki kapasitas 24 ribu orang, Presiden cek kesiapan Wisma Atlet tampung pasien COVID-19; 2020 [cited 2020 Sep 22].

7. Chen S, Zhang Z, Yang J, Wang J, Zhai X, Bärnighausen T, et al. Fangcang shelter hospitals: a novel concept for responding to public health emergencies. The Lancet. 2020;395(10232):1305-14.

8. Cai Y, Huang T, Xu G. The effects of "Fangcang, Huoshenshan, and Leishenshan" hospitals and environmental factors on the mortality of COVID-19. PeerJ. 2020;21(8):e9578.

9. Kementerian Kesehatan Republik Indonesia. Pedoman pencegahan dan pengendalian coronavirus disease (COVID-19); 2020

10. Burhan E, Susanto A, Nasution S, Ginanjar E, Pitoyo C, Susilo A, et al. Protokol tata laksana COVID-19. 3rd edition. Jakarta: PDPI, PERKI, PAPDI, PERDATIN, AIDAI press; 2020.

11. Zhao W, Yu S, Zha X, Wang N, Pang Q, Li D, et al. Clinical characteristics and durations of hospitalized patients with COVID-19 in Beijing: a retrospective cohort study. medRxiv; 2020.
12. Tian S, Hu N, Lou J, Chen K, Kang X, Xiang Z, et al. Characteristics of COVID-19 infection in Beijing. Journal of Infection. 2020;80(4):401-6

13. Michelen M, Jones N, Stavropoulou C. In patients of COVID-19, what are the symptoms and clinical features of mild and moderate cases?; 2020 [cited 2020 Sep 12]

14. Ma C, Gu J, Hou P, Zhang L, Bai Y, Guo Z, et al. Incidence, clinical characteristics and prognostic factor of patients with COVID-19: a systematic review and meta-analysis. medRxiv; 2020.

15. Swann O, Holden K, Turtle L, Pollock L, Fairfield C, Drake T, et al. Clinical characteristics of children and young people admitted to hospital with covid-19 in United Kingdom: prospective multicentre observational cohort study. BMJ. 2020;(370):m3249.

16. Tian S, Hu N, Lou J, Chen K, Kang X, Xiang Z, et al. Characteristics of COVID-19 infection in Beijing. Journal of Infection. 2020;80(4):401-6.

17. Noor F, Islam M. Prevalence of clinical manifestations and comorbidities of coronavirus (COVID-19) infection: a meta-analysis. Fortune Journal of Health Sciences. 2020;55-97.

18. Long Q-X, Tang X-J, Shi Q-L, Li Q, Deng H-J, Yuan J, et al. Clinical and immunological assessment of asymptomatic SARS-CoV-2 infections. Nature Medicine. 2020;26:1200-4.

19. Wang X, Guo X, Xin Q, Pan Y, Hu Y, Li J, et al. Neutralizing antibody responses to severe acute respiratory syndrome coronavirus 2 in coronavirus disease 2019 inpatients and convalescent patients. Clinical Infectious Diseases. 2019;(71):2688-94.

20. Fu L, Wang B, Yuan T, Chen X, Ao Y, Fitzpatrick T, et al. Clinical characteristics of coronavirus disease 2019 (COVID-19) in China: A systematic review and meta-analysis. Journal of Infection. 2020;(80):656-65.

21. Zhou F, Yu T, Du R, Fan G, Liu Y, Liu Z, et al. Clinical course and risk factors for mortality of adult inpatients with COVID-19 in Wuhan, China: a retrospective cohort study. The Lancet. 2020;395(10229):1054-62. 